\title{
Article
}

\section{Materiality Approach in Sustainability Reporting: Applications, Dilemmas, and Challenges}

\begin{abstract}
Yining Zhou
Southern Cross Business School, Southern Cross University, Tweed Heads, NSW, Australia, 2485.

Email: zhou_neil@yahoo.com; yining.zhou@scu.edu.au

Tel: +61451058411

Received: / Accepted: / Published:

Abstract:

Originated from financial reporting context, the concept of materiality has been applied in and contributed to sustainability reporting, by identifying, selecting, and prioritizing sustainability issues with significant impacts. This paper identifies two dilemmas that traditional stakeholder-approach confronts, and then analyzes how materiality-approach delivers advantage by addressing the dilemmas. This paper further observes two challenges for materiality-approach reporting: complexity interrelationship of sustainability issues; and subjectivity in materiality assessment. It argues that the two challenges are inherent and basic concerns for current sustainability accounting. This paper concludes that the road of materiality to sustainability reporting would be advanced with the progress of coping with the challenges. That is, extending our insight on the complex interrelationships of sustainability issues, and on subjectivity in materiality assessment, we would not only embrace a better materiality model to future effective sustainability reporting, but also open a door to view the fundamental theoretical concerns in contemporary sustainability accounting.
\end{abstract}

Key words: sustainability reporting; materiality; stakeholder; interrelationship; complexity; subjectivity; sustainability accounting

\section{Introduction}

The last decades have seen a revolution in corporate reporting - while at the end of 1980s, only two or three companies in the world issued their environmental and social reports, now majority of the world's largest businesses issue annually their 
sustainability reports covering financial environmental and social aspects, with millions of small and medium sized businesses all over the world are already reporting on their social and environmental performance [1] [21].

An underlying force for such trend lies in the increasing pressure and power by stakeholders who show interests on organizations' environmental and social behaviors [22]. In search for fulfilling needs of a wide-range of stakeholders, some businesses employ stakeholder- approach to sustainability reporting.

However this influential approach encountered some difficulties. One significant difficulty is that report preparers sink into the sea of data but still difficult to satisfy many stakeholders' needs. It leads sustainability reports to thick books with voluminous information; however stakeholders are still unsatisfied with the information that these reports provide.

The concept of 'sustainability materiality' has been introduced recently to corporate sustainability reporting. Materiality relates to the significance and reference of the reporting information to report users. It works as a filter to the data: let material issue within; while the immaterial without. In this way, materiality-approach focuses on only 'material information' and 'key areas', and is proved to an effective reform to stakeholder-approach.

What is 'sustainability materiality'? Are there any difference between sustainability materiality and financial materiality? How would application of materiality meet the challenges that confront traditional all-in-one approach reporting? And furthermore, can materiality provide an absolute solution to sustainability reporting? If not, how to improve it?

In answering these questions, this paper studies how materiality approach becomes an effective sustainability reporting model by addressing the dilemmas that traditional stakeholder-approach confronts. And it further reveals 'interrelationship' and 'subjectivity' as two challenges faced with materiality approach. It argues that the road of materiality towards future effective sustainability reporting needs to meet the two challenges.

\section{Materiality Concept: from financial to sustainability context}

Materiality is a key concept on financial reporting, auditing and accounting. Some accountant standards institutions give their own definitions for materiality, such as materiality in FASB Statement of Financial Accounting Concept No. 2 (SFAC No. 2). Financial Accounting Standards Board defines materiality as:

"The magnitude of an omission or misstatement of accounting information that, in the light of surrounding circumstances, makes it probable that the judgment of a reasonable person relying on the information would have been changed or influenced by the omission or misstatement."

Another influential definition is given by International Accounting Standards (IASs),

"Information is material if its omission or misstatement could influence the economic decisions of users taken on the basis of the financial statement. Materiality depends on the size of the item or error judged in the particular circumstances of its omission or misstatement. Thus, materiality provides a threshold or cutoff point rather than being a primary qualitative characteristic which information must have if it is to be useful."

Materiality known as 'financial materiality' is defined and applied in the context of financial accounting. However in an extended context on sustainable development covering financial social and environmental aspects, the definition of 'materiality' needs to be reassessed.

In sustainability reports, the scope is broadened to cover social and environmental as well as financial performance, with audiences of reports are extended from financial capital owners to a wide range of stakeholders. Then the concept of 
materiality would need to be reassessed in the new context. However current opinions have not yet achieved to a widely acknowledged definition on this "broadened materiality".

The Global Reporting Initiative guidelines (GRI), the world's first general sustainability reporting framework, locates materiality as a crucial principle of deciding what issues and indicators to include, omit, and emphasize in sustainability reporting. The latest G3 version puts as much emphasis on the underlying principles of inclusivity, materiality and completeness as it does on the list of standard disclosure issues.

"The information in a report should cover topics and indicators that reflect the organization's significant economic, environmental, and social impacts or that would substantively influence the assessments and decisions of stakeholders"

Some new development of the concept of "sustainability materiality" arose in the area of Auditing and Assurance. AccountAbility provides AA1000 Assurance Standard (AA1000AS), a sustainability assurance standard on materiality.

"A material issue is an issue that will influence the decisions, actions, and performance of an organization or its stakeholders."

"That the Assurance Provider states whether the Reporting Organization has included in the report the information about its sustainability performance required by its stakeholders for them to be able to make informed judgments, decisions and actions."

\section{Addressing Dilemmas}

\subsection{Two Dilemmas in Traditional Stakeholder Approach}

Widely applied to nowadays' sustainability reporting, stakeholder-approach does not concentrate on investors merely, but tries to recognize the different needs and views of multi-stakeholder. This approach has been developed as the increasing power and pressure by the stakeholders who show interests on an entity's social responsibility which include its environmental, social and economic performance.

But a difficulty stands, in practical terms, that how to meet diverse needs of stakeholders. Such difficulty, on which current stakeholder-approaches likely do not have effective resolutions, results in 2 dilemmas.

\section{Dilemma 1: Voluminous data vs. more information in need}

The wide-range stakeholders usually demonstrate diverse interests and demands on the report. Then to meet those diverse needs, businesses must collect and report far more data than before - data in sustainability reports are far more than in financial statements. A remarkable consequential phenomenon is that huge time and cost has been spent on dealing with the booming data, however effectiveness seems to be little - some stakeholders still feel a lack of necessary information. As Rafael Fernandez de la Conazon, Telefonica addresses:

'Our stakeholders were telling us on one hand that the report is far too long. But if we ask them what we are missing, they are also demanding more and more information to be included.' [21]

That may be an inevitable result from the proposition of this approach: to meet diverse needs of multi-range stakeholders; however, the more stakeholders that an organization seeks to satisfy, more data it needs to prepare.

Dilemma 2: $\quad$ mechanized reporting vs. selective reporting (strictness vs. flexibility)

'Mechanized reporting' means that reporting items are driven automatedly and prioritized mechanically from the database by guidelines and management system. For instance, GRI Sustainability Reporting Guidelines (G3) have been developed 
through trying to achieve consensus on views of multi-stakeholders: what items are important and how to measure it. Such guidelines become globally adopted in reporting, '(even before 2002) with estimates of several thousand companies already using the guidelines in their own sustainability reporting' [36]. But the guidelines or reporting systems, focusing on general views of stakeholders, may ignore different reporting contexts: particular issues might be misstated or ignored.

From this point of view, flexibility should be advocated and supported in reporting. However it is evident that excessive flexibility for report preparers would result in "selective reporting" effect where companies would choose, omit or emphasize items on their behalf rather than on the ground of fairness and objectiveness. In these cases, one company reports or emphasizes some matters, and another company may emphasize other matters, even they are operated in the same industry. The reporting entities tend to report those issues which can highlight their own advantages. Take oil industry as an example, [31] [32] [33] emphasize the 'green energy' aspects by highlighting green honors it has been awarded and the praise of Non-government Organizations; Comparatively, to distinguish "greenness", [17] [18] [19] seldom mention such 'greenness awardships', but emphasizes on the leading energy technological status by highlighting research expenditure, and qualifications of relevant researchers and technicians.

A dilemma faces the reporters. On the one hand, focusing on flexibility is likely to lead to "selective reporting": to report and emphasize issues in good and positive perspectives, making sustainability reports like an advertisement. On the other hand, to obey strict standards, guidelines and instructions may result in 'mechanised reporting': the ignorance of differences in reporting contexts may result in the misstatement of some material issues not listed in preset general framework.

\subsection{How Materiality-approach Address the Dilemmas}

As Stakeholder Management is becoming critically important in businesses' agenda, some models focusing on 'managing stakeholder relationships' have been developed beyond just 'recognizing stakeholders'; one of them is to classify stakeholders on a matrix with 4 segments with two axes as 'power held' and 'interest in the entity's performance', in order to indicate how to take different actions on different stakeholders, as the following figure.

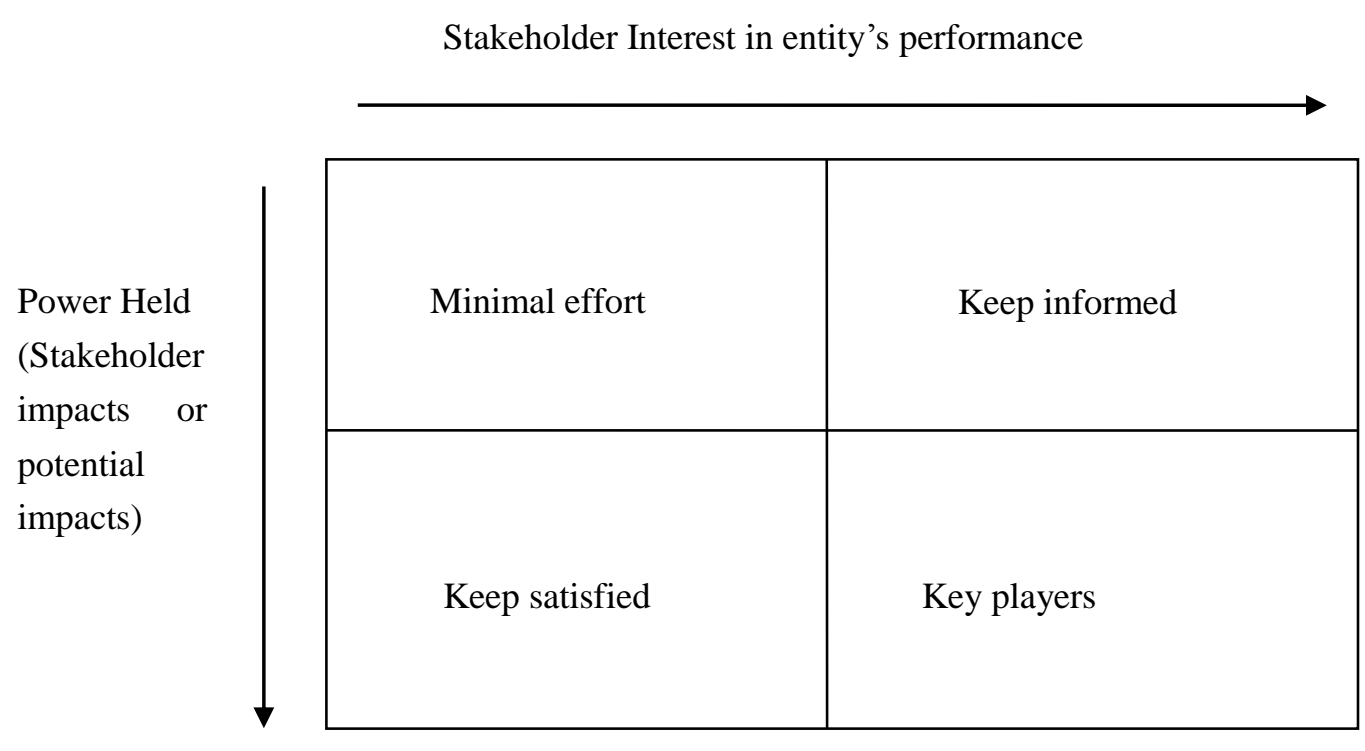

Stakeholder Map

Source: [2] 
For example, with high interests and high influence on the entity, investors are put in the segment 'KEY Player'; and some community representatives and NGOs (such as environmental groups) are often deemed as 'Keep informed', with high interest but low influence.

The 'Stakeholder Map' also helps to discern the motives of sustainability reporting, and the value of materiality on reporting.

·Items which associate with 'key players' would be considered most important in Stakeholder Management, and hence would be accounted and reported for. In normal cases, investors are considered key players for an entity. Among them, 'responsible Key players', especially 'green investors' and 'green customers' initiate basic forces to the birth and development of sustainability reporting.

-Assessment of materiality. This model provides two analytical indicators for material issues as for stakeholders: if an issue holds both high interest and high influence of stakeholders on the entity, it must be material. In fact, if link material issues to stakeholders in the same map, we may achieve such a conclusion: the more material an issue is, the more close relation it holds to 'key stakeholders' (i.e., key players).

Some companies have been to develop materiality approach to reporting. A typical example is Ford Motor's 'Materiality Matrix' for the analysis of sustainability issues.

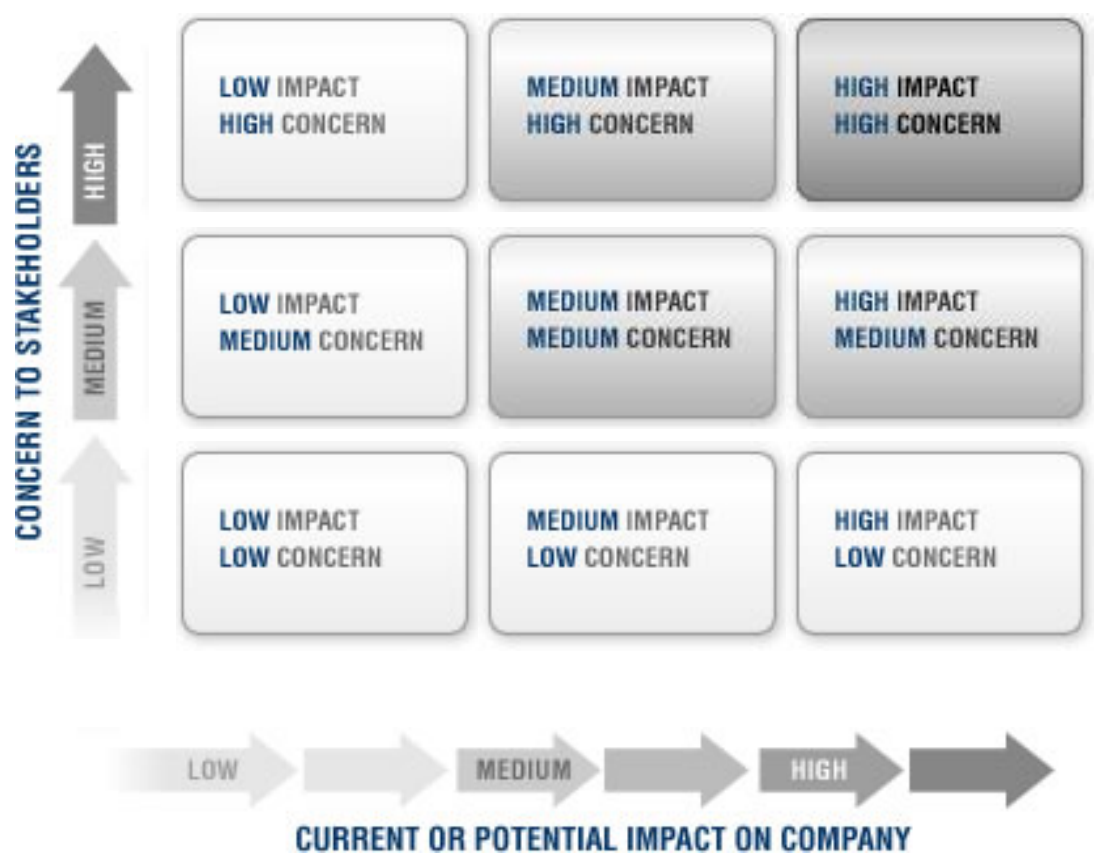

Issues in this box set the agenda for Ford Motor's printed report

Issues in these boxes set the agenda for this report and future reporting

Issues in these boxes are not currently covered by reporting

The two indicators, 'level of concerns to stakeholders' and 'current or potential impact on company' allocate sustainability issues of Ford Motor into 9 sectors. But it is noticeable that both indicators in Ford Matrix are likely the same as in 'stakeholder mapping'. From this perspective, 'stakeholder relevance' and 'stakeholder impacts' constitute a common ground, on which the significance and importance of issues are accounted for, would be seen from Ford's Materiality Matrix and 'Stakeholder Mapping' and, moreover, be evidently exemplified by other typical materiality models as in BP, BT and MRT.

There are 2 other well-known materiality matrix/ models: BP Materiality Matrix and BT Materiality Matrix. 
BP's indicators are 'public exposure and awareness' and 'potential impacts on BP's ability to deliver strategy'; BT's indicators are 'significance to BT stakeholders and society' and 'significance to BT'. But we may find that these materiality matrixes have the same root - to divide sustainability issues by two indicators, one associates with stakeholders' interest, the other relates to stakeholders' impact on the entity itself.

There are also a few examples of adopting 'risk-focused' approaches to reporting - the higher risk that an issue effects on the company, the higher likelihood it should be reported. See the example of MTR (Hongkong). MTR's materiality model is a three-dimensional map with 3 axes, 'stakeholder interest', 'impacts on MTR's ability to deliver on strategy' and 'business risks", with 'risk' as a core indicator, "this mapping exercise graphically displays our reporting strategy for the ranking of business risk', as quoted in MTR statement of 'materiality mapping'.

But in nature, 'risk' would be often considered as 'potential or possible serious impact on the entity', then be included in the indicator 'stakeholder impact', so I would here conclude risk-approach as a sort of materiality-approach.

The two indicators, stakeholder concerns and stakeholder impacts, provide a guideline on assessing materiality, although complex situations still remain to be examined in the way towards practical application.

The above discussions tend to reveal an evolutionary relationship between materiality approach and stakeholder-approach: stakeholder-approach tries to select issues from the general view of a wide-range of stakeholders, whilst materiality-approaches select issues focusing on the view of key stakeholders (those with high stakeholder relevance and high stakeholder impact).

Now return to the dilemmas that stakeholder-approach confronts. We could here see how materiality addresses the two dilemmas in stakeholder-approach.

(1) For the first dilemma, materiality is used as a filter to the 'data sea', and hence, only 'material information' remains in reporting. So information needs not to satisfy the 'a wide range of stakeholders', but just limit the scope to 'key' stakeholders with higher interest and higher impacts.

(2) The second dilemma is addressed in that materiality itself is a measurement instrument to prioritize data. Then materiality assessment process would prevent 'mechanized reporting', for entities can develop the materiality framework based on their own operating and reporting contexts. Meanwhile, it also avoids excess flexibility in reporting and thus lessens 'selective reporting' effect for only high material issues would be included in the report.

\section{Challenges for Materiality Approach: Interrelationship \& Subjectivity}

As analyzed before, the ongoing materiality-approach would address the dilemmas in stakeholder-approach. But is materiality approach perfect for sustainability reporting?

Krista Gullo (manager of Ford Motor) comments:

"We wanted this (materiality-approach) to be a more objective way to define issues for the report but it wasn't a completely scientific approach. It was difficult to balance the desire to be objective with the feeling that this was also a subjective process. During the first round, this was compounded by the fact that we didn't have data for all stakeholders. The other challenge in terms of prioritization is that sustainability issues tend to be interrelated so there was a frustration in trying to separate out these issues so distinctly. "'[21]

This statement implies two challenges for materiality approach.

Challenge 1: sustainability issues tend to be interrelated and thus difficult to separate out them.

Challenge 2: this approach is also a subjective process 


\subsection{Challenges 1: interrelationships of sustainability issues}

Now investigate the first challenge: interrelated issues make it difficult to separate them distinctly in prioritizing and reporting. GRI (G3) provides three categories (economic social and environmental) including a list of indicators to identify sustainability issues. In practical terms, it is not rare that one sustainability issue relates directly or closely to other issues in different categories and different aspects of a category. To take a trivial instance: a factory plan to 'renew a product line' for more environmental and productive performance, then a series of issues would be yielded in different aspects:

- economic perspective: renewing expenditure, non-current asset, tax relief, governmental grant on environment, expected productivity, cost on raw material (often more expensive for better environmental impacts)

-Environmental perspective: GHG emissions, SO2 emissions, energy efficiency, noise, environmental impacts of disposal old machines.

-Social perspective: employee (working condition improved as being more environmental friendly), local community (less noise, waste water to local communities), local employment.

These issues, which are obviously concerning sustainable development, are connected together from the activity 'renewing a product line'.

There are three cases extracted from [2]. We can see how financial, social and environmental issues are interrelated in these cases.

Case 1: Glowball is a company that pipes gas from offshore gas installations to major consumers. The company purchased its main competitor during the year and found that there were environmental liabilities arising out of the restoration of many miles of farmland that had been affected by the laying of pipeline. There was no legal obligation to carry out the work but the company felt that there would be a cost of around $\$ 150$ million if the farmland was to be restored.

Reporting: of relevance to the farmland restoration is IAS 37 Provisions, contingent liabilities and contingent assets. Provisions for environmental liabilities should be recognized where there is a legal or constructive obligation to rectify environmental damage or perform restorative work. The mere existence of the restorative work does not give rise to an obligation and there is no legal obligation. However, it could be argued that there is a constructive obligation arising from the company's approach in previous years, which may have given rise to an expectation that the work would be carried out. If this is the case, a provision of $\$ 150 \mathrm{~m}$ would be required in the financial statements. In addition, this provision and specific examples of restoration of land could be included in the environmental report.

Case 2: Most of the offshore gas installations are governed by operating licenses which specify limits to the substances which can be discharged to the air and water. These limits vary according to local legislation and tests are carried out by the regulatory authorities. During the year the company was prosecuted for infringements of an environmental law in the USA when toxic gas escaped into the atmosphere. In 20X2 the company was prosecuted five times and in 20X1 eleven times for infringement of the law. The final amount of the fine/costs to be imposed by the courts has not been determined but is expected to be around \$5million. The escape occurred over the seas and it was considered that there was little threat to human life.

Reporting: the treatment of the fine is straightforward: it is an obligation to transfer economic benefits. An estimate of the fine should be made and a provision set up in the financial statements for \$ $5 \mathrm{~m}$. This should be mentioned in the environmental report. The report might also put the fines in context by stating how many tests have been carried out and how many times the company has passed the tests. The directors may fell that it would do the company's reputation no 
harm to point out the fact that the number of prosecutions has been falling from year to year.

Case 3: the company tries to reduce the environmental impacts associated with the siting and construction of its gas installations. This is done in the way that minimises the impact on wild life and human beings. Additionally when the installations are at the end of their life, they are dismantled and are not sunk into the sea. The current provision for the decommissioning of these installations is \$215million and there are still decommissioning costs of \$407 million to be provided as the company's policy is to build up the required provision over the life of the installation.

Reporting: the environmental report should mention the steps the company is taking to minimise the harmful impact on the environment in the way it sites and constructs its gas installations. The report should also explain the policy of dismantling the installations rather than sinking them at the end of their useful life.

Currently the company builds up a provision for decommissioning costs over the life of the installation. However, IAS 37 does not allow this. Instead, the full amount must be provided as soon as there is an obligation arising as a result of past events, the settlement of which is expected to result in an outflow of resources. The obligation exists right at the beginning of the installation's life, and so the full $\$ 407 \mathrm{~m}$ must be provided for. A corresponding asset is created.

The above 3 cases indicate that 'interrelationship' makes sustainability reporting not as straightforward as in financial reporting. In case 1 , the 'constructive provision' of $\$ 150 \mathrm{~m}$ in financial statement relates directly to restoration of land in environmental category; in case 2, the 'obligation' $\$ 5 \mathrm{~m}$ (financial category) relates to 'environmental fine' (environmental category), emissions to air (environmental category), waste water (environmental category), threat to human life/safety (social category), and brand and reputation (likely in terms of goodwill or intangible assets, in financial category); In case 3 , such items are interdependent, minimising harmful impact (environmental category), relevant policy (environmental category), obligation $\$ 407 \mathrm{~m}$ (financial category), corresponding assets (financial category).

Researchers have acknowledged the phenomenon that sustainability issues are interrelated. [12] note 'the recognization of the world's environmental problems, like all the other major problems of our time, can not be understood in isolation. They are systematic problems, interconnected and interdependent', [9] describes the complexity of interrelationship in organizational level, 'If business performance is now to be expanded to include social, environmental, ecological and sustainable development aspects then the levels of complexity increase not in a marginal way but by factors of two, ten or a hundred dependent upon the industrial sectors under consideration.'

Consistent with this interrelationship view, some researchers argue that conventional tools lacking of holistic and wholeness scope on sustainability systems which constitute of complex interrelationship. As [12] note, '(the problems of complex interrelationship) are need a new kind systematic, or ecological, thinking to be understood or solved.'

[34] indicates 3 core components in sustainability issues:

a. Wicked problems: are described as having contradictory and variable requirements and effective solutions are difficult realised because of complex interdependences across a range of factors.

b. Uncomfortable knowledge: new and emerging knowledge that challenge our current beliefs and behaviors.

c. Clumsy solutions: applying conventional solutions to unconventional problems. Or in other words, traditional approaches to 'wicked problems' tend to be ineffective and clumsy.

In his view, interrelationship (interdependence) of sustainability issues is complex. And this complexity limits our ability to understand wicked problems and seek effective solutions to them.

[24] asserts that sustainability can 'only' be fully understood and effectively pursued by viewing human communities 
(including their attendant ecological systems) as complex systems. Furthermore, he states that the "environment" is not external to society but a part of complex human systems through the myriad interactions of individual human agents with the non-human world and through their internal models, by which they give meaning to their individual experiences.

From this point of view, the challenge, 'complex interrelationship' is an inherent concern for sustainability accounting, and the search for resolutions on this challenge meets limitations of our current knowledge. To address this challenge, new development on accounting tools and thinking is demanded.

\subsection{Challenge 2: Subjectivity in Assessment}

Turn to the second challenge, 'the feeling that this was also a subjective process'. Materiality-approaches, as well as other sustainability accounting methods, must involve the subjective element to some extent because different accountants commonly have different views on sustainability issues.

\subsubsection{Subjectivity in materiality assessment of accountants}

In financial context, accounts /issues are evaluated in terms of a uniform value (i.e. money or monetary terms), on which accounting tools and techniques are grounded; however, in sustainability context, we can no longer recognize issues through such a uniform 'value'. I suggest that subjectivity is unavoidable in any accounting approaches including materiality-approach.

[9] asserts that subjectivity is inevitable: 'Accountants cannot give an 'objective' picture of the reality of business impacts in the ecosystem since this impact is determined by both the 'idea' behind our perception of the impact and the creative response of the ecosystem and ourselves with regards to the impact. There is no detached position from which we can observe objectively - our very acts of observation changed by observer and observed. It is pretence, abdication, cant, deception, foolhardy, inefficient and time-wasting to pretend that objectivity can be achieved.'

To make the explanation of subjectivity plain, a Hindoo fable, 'blind men and an elephant', is here affiliated to basic reasons of 'subjectivity'. This story is sourced from 'Upanisad', a philosophy book with a history of thousands of years. (Note: Some historians assert that the book of Upanisad was written before BC. 1500, and finished about B.C. 600 in Ancient Indian. The word Upanisad, literally means esoteric knowledge.)

Six blind men came to 'observe' an elephant. The first men happened to fall against the broad and sturdy side, he said, 'the elephant is very like a wall'; the second one, feeling the round smooth and sharp truck, cried, 'that is clear, the elephant is very like a spear.'; The third took the squirming trunk and said, 'the elephant is very like a snake.'; The fourth reached the elephant's knee, speaking, 'this beast is very like a tree.'; the fifth touched the ear and said, 'this animal is very like a fan.'; the sixth seized the swinging tail and told, 'the elephant is very like a rope.' Then they could not agree with each other, and all of them thought their own observation was right, disputing loud and long.

We can take the elephant as the reporting target, and these blind men as reporters. This story indicates six different results on the same reporting target, and in the same observing approach, 'touching'. It also indicates the diversity in accountants' assessment

- The target system has various perspectives for observation; in this fable, the elephant has at least 6 perspectives for observers and would be more if observe the skin, the weight, and so on.

- Limitations in observers' perception. They would observe and report only through one or some (not all) perspectives concerning them. 
- Limitation on description. The description (words to report) would be limited on a basis of their past experience that they held. For example, the second men might not describe (report) other parts than the truck, but describe it from his own experience. (If he were unfamiliar with spears but familiar with cows, he might describe it as 'very like a horn'.)

\subsubsection{Subjectivity in Stakeholder opinions}

'Materiality is a principle which is related to relevance and which is sometimes referred to as a 'threshold characteristic'. Furthermore, what will be considered as materiality by one user group may be different from the view of another group.' European Federation of Accountants: FEE Discussion Paper towards a Generally Accepted Framework for Environmental Reporting, 1999

As indicated above, 'stakeholder interest' and 'stakeholder influence' are of key elements on determining material effects. But how can we measure the two key elements in practice? [21] once made interviews for some report preparers who adopted materiality-approach, and discovered that they tend to outline 'stakeholder views / opinions' as most important determinant for materiality of issues. As Claus Frier (Novozymes) notes, 'when we are working with these issues, we are looking at issues that are relevant to us and to our stakeholders. We have specifically listed that stakeholder dialogue is an important way of working for Novozymes' [21]. And Darryl Knudsen (Gap Inc.) addressed the like instances, 'More like we engage with stakeholders on one piece of the process then step back and look at the big picture and reflect on the choices we've made.' [21]

Even if stakeholder opinions reflect material effects of issues, to what extent we should depend on stakeholder opinions in assessing materiality?

In reality, it is not rare that stakeholders do not achieve a consensus on issues. Their opinions tend be diverse, or sometimes, conflicting and incompatible due to their differing value, expectation and interest [29] [27] [14]. Stakeholder views, as a basis for accountants to assess materiality, are also a product of subjectivity.

\section{Conclusion}

Originated from financial reporting context, the concept of materiality has been applied in and contributed to sustainability reporting, by identifying, selecting, and prioritizing sustainability issues with significant impacts. Materiality-approach delivers advantage compared to traditional stakeholder approach, which tries to satisfy all stakeholders' information needs however confronts two dilemmas: data sea versus stakeholder requirements; and selective reporting versus mechanized reporting. Materiality addresses the two dilemmas, by working as a filter to the data sea while satisfying key stakeholders, and by providing a balance on 'selective reporting' and 'mechanized reporting'. This paper further identifies two challenges for materiality-approach: 'interrelaitonship' and 'subjectivity'. It analyses the two challenges as inherent and basic concerns for current sustainability accounting. It argues that the road of materiality to sustainability reporting would be advanced with the progress of coping with the challenges. That is, extending our insight on the complex interrelationships of sustainability issues, and on subjectivity in materiality assessment, we would not only embrace a better materiality model to future effective sustainability reporting, but also open a door to view the fundamental theoretical concerns in contemporary sustainability accounting.

\section{Conflict of Interests}

The author declares no conflict of interests. 


\section{Reference List}

1. ACCA, Corporate Report, BPP Publishing, London, 2007.

2. ACCA, Performance Management, BPP Publishing, London, 2007.

3. BP Report 2004, available in www.BP.com

4. BP Report 2005, available in www.BP.com

5. BP Report 2009, available in www.BP.com

6. BP, BP Materiality model, available in www.BP.com

7. BT, BT's Materiality Matrix, available in www.bt.com

8. Birkin, F, Steps to Natural Capitalism, Sustainable Development 2001. vol. 9, no. 1, pp 47-57.

9. Birkin, F, The Art of Accounting for Science, Critical Perspectives on Accounting 2000, vol. 11, no. 3, 2000, pp. 289-309

10. Birkin, F. K, The Ecological Accountant: from the Cogito to Thinking Like a Mountain, Critical Perspectives on Accounting 1996, vol.7, no.3, pp. 231-257.

11. Bryman, A \& Bell, E, Business Research Methods, Oxford University Press, UK, 2003.

12. Callenbach, E. \& Capra, F. EcoManagement - The Elmwood Guide to Ecological Auditing and Sustainable Business, Wiley, QLD, Australia, 1993.

13. Easterby-Smith, M., Thorpe, R. \& Lowe, A, Management Research: An Introduction (2nd Edition), SAGE Publishing, London, 2002.

14. Elias A, Jackson L \& Cavana Y, Changing positions and interests of stakeholders in environmental conflict: a New Zealand transport infrastructure case, Asia Pacific View Point 2004, 45(1): 87 - 104.

15. Elkington, J, Cannibals with Forks: The Triple Bottom Line of 21st. Century Business. Capstone Publishing, London, 1998.

16. Epstein, M. J, Measuring Corporate Environmental Performance, IRWIN, Chicago, 1996.

17. ExxonMobil Report 2004, available in www.exxonmobil.com

18. ExxonMobil Report 2005, available in www.exxonmobil.com

19. ExxonMobil Report 2010, available in www.exxonmobil.com 
20. Ford Motor's Materiality Matrix, available in www.ford.com

21. Forstater, M, Zadek, S, Evans, D, Knight, A, Sillanpaa, M, Tuppen, C \& Warris, A, the Materiality Report: Aligning Strategy, Performance and Reporting, AccountAbility, London, 2006.

22. Gray, R \&.Bebbington, J, Accounting for the environment, SAGE, London, 1993.

23. Gray P., Owen, D. \& Adams, C, Accounting and accountability, Prentice Hall, London, 1996.

24. Harrison, N, Constructing Sustainable Development, SUNY, Press, London, 2000.

25. Isaak, R, Green Logic: Ecopreneurship, theory and ethics, Greenleaf, Sheffield, UK, 1998.

26. Mathews, M.R, Socially Responsible Accounting, Chapman \& Hall, London, 1993.

27. Mitchell R, Agle B \& Wood D, Toward a theory of stakeholder identification and salience: defining the principle of who and what really counts, Academy of Management Review 1997, 22(4): 853 - 886.

28. MTR materiality mapping, available in www.mtr.com.hk/eng/sustainability

29. Ogden S \& Watson R, Corporate performance and stakeholder management: balancing shareholder and customer interests in the U.K. privatized water industry, Academic of Management Journal 1999, 42(5): 526 - 538.

30. Schaltegger, S, Corporate Environmental Accounting, Wiley, QLD, Australia, 1992.

31. Shell Reports 2004, available in www. Shell.com

32. Shell Reports 2005, available in www. Shell.com

33. Shell Reports 2009, available in www. Shell.com

34. O’Riodan, T (2009), Reflections on the pathways to sustainability, in W.N. Adger \& A. Jordan (eds), Governing Sustainability, Cambridge University Press, Cambridge, 2009, pp.307 - 328.

35. Zadek, S. \& Raynard, P, the Future of Sustainability Assurance, Certified Accountants Educational Trust, UK, 2004.

36. Zadek, S. \& Merme, M, Redefining Materiality: Practice and Public Policy for Effective Corporate Reporting, AccountAbility, London, 2003.

(C) 2011 by the authors; licensee MDPI, Basel, Switzerland. This article is an open access article distributed under the terms and conditions of the Creative Commons Attribution license (http://creativecommons.org/licenses/by/3.0/). 